\title{
TAKE A (COGNITIVE) LOAD OFF: CREATING SPACE TO ALLOW FIRST-YEAR LEGAL WRITING STUDENTS TO FOCUS ON ANALYTICAL AND WRITING PROCESSES
}

\author{
Terri L. Enns \& Monte Smith*
}

Most legal writing and analysis professors would say that they are teaching fundamental concepts of writing and analysis as they guide students through the generation of a series of legal documents. ${ }^{1}$ Writing and analysis are the processes, and the documents are the products. However, students' grades are based primarily or exclusively on the products, and students can be frustratingly fixated solely on the documents they are drafting at any moment. The fact that the instructor is focused on teaching processes does not automatically mean that the student is learning them. This near-sightedness on the part of novice lawyers is understandable; in fact, it is inevitable. They want to perform the graded task well. They will carefully apply everything they hear in class and read in a textbook to the project they are working on so that they can achieve the best possible grade. Along the way, they may believe that they are keeping the broader lessons about analysis and writing in their peripheral vision, but they lose some of the legal writing doctrine from the first assignment by the first draft of the second. ${ }^{2}$

*. (C) 2015, Terri L. Enns and Monte Smith. All rights reserved. Terri L. Enns is a Clinical Professor of Law and Monte Smith is Assistant Dean for Academic Affairs at the Moritz College of Law at The Ohio State University. The Authors thank Jourdan Day for her research assistance and colleagues Mary Beth Beazley, Linda Berger, Terrill Pollman, and Anne Ralph for their helpful suggestions.

1. See Ellie Margolis \& Susan L. DeJarnatt, Moving Beyond Product to Process: Building a Better LRW Program, 96 SANTA ClaRA L. Rev. 93, $98-99$ (2005); Jo Anne Durako et al., From Product to Process: Evolution of a Legal Writing Program, 58 U. PITT. L. REV. 719, 719-20 (1997).

2. Others have observed and described this phenomenon. Here is one example:

In the rush to professionalize the discipline of legal writing and show skeptics that there is a "content" to the subject and that writing can be taught, perhaps the pendulum has swung too far in favor of "content driven learning." Perhaps, in focusing on content like CREAC and Bluebook citations, legal writing faculty have neglected 
In this Article, we identify some ways in which cognitive load impedes first-year law students' ability to learn analytical and writing processes at the same time that students are producing a written analysis for a grade. We describe exercises we have used in our first-year legal writing and analysis classes that remove the product from our students' fields of vision so that students focus on analytical processes, writing processes, or both. We summarize some learning theories that suggest that such exercises likely succeed in teaching analytical and writing doctrine. Finally, we propose devoting a portion of the legal writing and analysis course exclusively to process to move students toward deep understanding of analytical and writing processes as a primary goal rather than a tangential aspiration.

\section{EXCESSIVE COGNITIVE LOAD BLOCKS ONE OF THE IMPORTANT GOALS OF THE FIRST-YEAR LEGAL WRITING AND ANALYSIS COURSE}

If the problem is that students cannot focus on products and processes simultaneously, a source of the problem is cognitive load. "Cognitive load" is the term cognitive psychologists use for the mental burden that managing working memory imposes on a person. ${ }^{3}$ Working memory is "highly related" to short-term memory but also encompasses central executive processes. ${ }^{4}$

legal analysis and thinking. The faculty may have inadvertently become "contentcentered teachers [who] believe that merely providing exposure to the ideas of the discipline will cause students' thinking to evolve naturally over time." Some legal writing faculty may even believe that "the capacity to think is innate and that, therefore, spending valuable class time promoting changes in thinking seems unnecessary or even misguided." Legal writing faculty need to turn away from this "banking" approach to education and return to a more instrumental view of teaching thinking and writing. Faculty need to explicitly teach students thinking strategies and make the students conscious of their cognitive processes. Faculty also need to continue to explore how their students' thought processes shape their students' writing and vice versa.

Christine M. Venter, Analyze This: Using Taxonomies to "Scaffold" Students' Legal Thinking and Writing Skills, 57 MERCER L. REV. 621, 625 (2006) (footnotes omitted).

3. Fred Pass et al., Cognitive Load Theory: Instructional Implications of the Interaction Between Information Structures and Cognitive Architecture, 32 InSTRUCTIONAL SCI. 1, 2 (2004). Joseph M. Williams wrote about the cognitive burden created by legal writing and analysis tasks in On the Maturing of Legal Writers: Two Models of Growth and Development, 1 Legal Writing 1, 15 (1991).

4. Randall W. Engle et al., Working Memory, Short-Term Memory, and General Fluid Intelligence: A Latent-Variable Approach, 128 J. EXPERIMENTAL PSYCHOL. 309, 326 (1999). "The central executive component is the source of controlled attention that can be used to 
Working memory encompasses information activated in the shortterm memory and the central executive processes required to access and use that information. ${ }^{5}$

Cognitive load theorists opine that the process of learning complex new information can exhaust a student's finite working memory, perhaps capable of holding as few as two or three elements at a time. 6 The complexity of the "element interactivity"the interaction between various elements of the material to be learned-alters cognitive load. ${ }^{7}$ Thus, the complicated process of analyzing legal problems, researching their possible solutions, and communicating that analysis in writing can overwhelm students' working memories, leaving no space for the conscious acquisition of more broadly-applicable writing doctrine. ${ }^{8}$

Learning theorists identify three types of cognitive load. First, "intrinsic cognitive load" is the difficulty inherent in the material to be learned, caused by the complexity of the element interactivity. 9 Second, "extraneous cognitive load" is unnecessary to the immediate learning objective and interferes with learning; extraneous cognitive load is often a function of instructional design and, thus, may be within the control of the educator. According to John Sweller, acknowledged as a founder of cognitive learning theory, ${ }^{10}$ instruction is "likely to be ineffective" when it "unnecessarily introduces interacting elements that should be eliminated." 11 The third type, "germane cognitive load," is a subset of the first and generally refers to the amount of intrinsic load that the working memory can effectively use for developing schema, the structures of long-term memory. ${ }^{12}$ Instructional design can regulate germane cognitive load to some extent; thus, the educa-

achieve activation of long-term traces through controlled retrieval, maintain activation through various means, or possibly even dampen activation through inhibition." Id. at 310 ; see also id. at 311 fig. 1.

5. Id. at $312-13,326$.

6. Fred Paas et al., Cognitive Load Theory and Instructional Design: Recent Developments, 38 EDUC. PSYCHOLOGIST 1, 2 (2003); John Sweller, Cognitive Load Theory, Learning Difficulty, and Instructional Design, 4 LEARNING \& INSTRUCTION 295, 299 (1994).

7. Paas et al., supra note 6 , at 1.

8. See Williams, supra note 3, at 8 .

9. John Sweller, Cognitive Load Theory: Recent Theoretical Advances, in CoGNITIVE LOAD THEORY 29, 40-41 (Jan L. Plass et al. eds., 2010).

10. Roxana Moreno \& Babette Park, Cognitive Load Theory: Historical Development and Relation to Other Theories, in COGNITIVE LOAD THEORY, supra note 9, at 9, 11.

11. Sweller, supra note 9, at 42-43.

12. Id. at $43-44$. 
tor's goal is to permit the amount of load that optimizes learning by paying careful attention to a learning task's intrinsic cognitive load and deliberately reducing the extraneous load. ${ }^{13}$

Imagine a group of students tasked with learning a new piece of music, sung in a foreign language. To learn the music, they will have to know the notes, understand the rhythm, pay attention to dynamic markings, and pronounce the text. All of those components contribute to the intrinsic load of learning the music. If the instructor teaches all of those elements by randomly asking four students at a time to perform the piece in front of the group, the extraneous load added by fear of failing in front of peers will probably hinder learning for most students. If, instead, the instructor asks the group to sing the notes using the sound "nah" instead of sounding out the unfamiliar language, and indicates that the group may ignore dynamic markings for the first reading, the germane load is probably within the working memory of the students, and they can begin learning.

Given that working memory is limited, a goal of learning is to move information from working memory into long-term memory. Cognitive load theorists posit that long-term memory can store vast amounts of information by linking it in "chunks" or "schema": "cognitive constructs that incorporate multiple elements of information into a single element with a specific function." ${ }^{14}$ Without organizing information into these larger constructs, our working memories would continually be "the bottleneck[s] that constrain[] learning." 15

So, our first-year legal writing students are not ignoring what we are trying to teach; rather, they cannot learn as many things as we want them to learn, all at the same time. They are marshaling their limited working memories in the most expedient fashion, giving the lion's share of their attention to the most immediate task. ${ }^{16}$ That task is not learning writing and analysis processes but producing a document about a legal issue or two,

13. Paas et al., supra note 6 , at 2

14. $I d$.

15. Deborah Jones Merritt, Legal Education in the Age of Cognitive Science and Advanced Classroom Technology 9 (Public Moritz Coll. of Law, Pub. Law \& Legal Theory, Working Paper No. 94, Ctr. for Interdisciplinary Law and Policy Studies, Working Paper No. 63, 2007), available at htp://ssru.com/abstract $=1007800$

16. Terrill Pollman, The Sincerest Form of Flattery: Examples and Model-Based Learning in the Classroom, $64 \mathrm{~J}$. LEGAL EDUC. 298, 300 (2014). 
often novel issues that take up a significant portion of the students' working memories with the issues' special vocabulary, rules, case facts, and all other bits of information that the students must comprehend. We should not wonder that students push analytical and writing processes to the intellectual margins. Those processes are largely extrinsic to the immediate task of producing a document for a grade. ${ }^{17}$

Learning theory offers some solutions to the tyranny of the product over the process. A promising means for reducing cognitive load to provide space for learning analytical and writing processes is the temporary elimination of the product. If analytical doctrine is introduced when the immediate need to produce a written document does not divert students' working memories, the cognitive space occupied by the information required to complete that document will open. 'The students' finite working memories will be available to focus entirely on acquiring doctrine.

Our study of cognitive load has persuaded us that we can design learning tasks for first-year law students that will allow them to learn more deeply the doctrine of legal writing and analysis. The exercises we describe in this Article exemplify such tasks. We designed these exercises independently of one another, but we were both attempting to create opportunities for students to observe the analytical and writing processes outside of the confines of their own writing.

\section{LEARNING THEORIES}

Building on these theories, described above in only the broadest strokes, the next section focuses on some teaching techniques employed in the exercises that this Article advocates. Specifically, this section introduces techniques such as scaffolding, discovery learning, and advance organizers.

\section{A. Scaffolding Allows Novices to Build Schema}

Cognitive load theory has tremendous implications for "complex learning." 18 Producing well-researched, well-analyzed, and

17. $I d$.

18. "Complex learning involves the integration of knowledge, skills and attitudes; the coordination of qualitatively different constituent skills, and often the transfer of what is learned in the school or training setting to daily life and work settings." JEROEN J. G. VAN 
well-written legal documents certainly meets the requirements for a complex task, as do most other legal tasks for which we are training our students. We have all seen students who can understand the issues and perform excellent research, yet who cannot communicate their analysis in writing. We have seen students who write beautiful sentences but cannot meet the organizational expectations of a legally trained audience. We have seen students who can analyze the legal issue and can write their analyses in a clear fashion but cannot find and fix spelling and citation problems. These students can all benefit from instruction that reduces the cognitive load and allows them to focus their attention on only some elements of the task before attempting to craft a full legal memorandum.

One of the chief means of reducing cognitive load is through scaffolding: support and guidance provided by the instructor, reduced over time as the student becomes more accomplished. ${ }^{19}$ By retaining the complexity and integrity of the whole but providing support for those parts of the task that the student cannot yet accomplish, scaffolding permits the student to accomplish a task that the student could not accomplish on her own. ${ }^{20}$ As the student progresses, the teacher fades the scaffolding until the student can accomplish the whole task unassisted.

Some common types of scaffolding include "providing hints, prompts, and feedback; modeling the use of cognitive strategies by thinking aloud; presenting cue cards, checklists, and process worksheets; asking leading questions; and giving part of a solution." ${ }^{21}$ These teaching methods are all familiar to legal

Merriënboer \& Paul A. Kirschner, Ten Steps to Complex Learning 54 (2007): A Systematic APProaCh to Four-Component Instructional DeSign 54 (2007). This definition comports with the Carnegie Report's first recommendation for improving legal education:

To build on their strengths and address their shortcomings, law schools should offer an integrated, three-part curriculum: (1) the teaching of legal doctrine and analysis, which provides the basis for professional growth; (2) introduction to the several facets of practice included under the rubric of lawyering, leading to acting with responsibility for clients; and (3) exploration and assumption of the identity, values and dispositions consonant with the fundamental purposes of the legal profession. Integrating the three parts of legal education would better prepare students for the varied demands of professional legal work.

William M. Sullivan et al., Educating Lawyers: Preparation for the Profession of LAW 12-14 (2007).

19. VAN MERRIËNBOER \& KIRSCHNER, supra note 18 , at 18

20. Id. at 54 .

21. Jeroen J. G. van Merriënboer et al., Taking the Load off a Learner's Mind: Instruc- 
educators, but a more comprehensive understanding of their role in supporting first-year legal writers may promote their increased use.

When scaffolding techniques are used, the goal is not to have students practice individual and discrete skills. The examples of scaffolding listed above maintain the integrity of the entire task rather than providing practice for discrete skills. ${ }^{22}$ An example of a scaffolded learning experience that uses a part-solution is a closed universe legal writing and analysis exercise, because even though students receive the research, they must still conduct the full analysis and create the document. According to van Merriënboer and Kirschner, breaking complex domains into separate parts has had "disastrous effects" for vocational and professional education. ${ }^{23}$ They posit that professional competencies require an integrated knowledge base if they are to be transferred to new situations, and "part-task approaches to sequencing and instructional design models driven by separate objectives do not work well for complex performances that require the integration of skills, knowledge, and attitudes and the extensive coordination of constituent skills in new problem situations . . .."24 If the goal of learning is to generate schema, the weakness of the part-task approach is that it provides no certainty that students will link information meaningfully. Approaches that retain the integrated whole, while gradually scaling back scaffolding as the learners gain competence, make appropriate linking more likely. ${ }^{25}$

The gradual reduction of support, known as fading, is critical to scaffolding. Once students develop schema, the positive effects

tional Design for Complex Learning, 38 EDUC. PSYCHOLOGIST 5, 6 (2003).

22. Van Merriënboer and Kirschner describe three whole-task methods: simplifying conditions, emphasis manipulation, and knowledge progression. VAN MERRIËNBOER \& KIRSCHNER, supra note 18, at 63.

23. Id, at 7 .

24. Id at 6 . Cognitive learning theory does find a role for "part-task practice," but only for those skills that need to become automated and are required regardless of the specific problem to be solved, and only if those skills need additional practice beyond that of the integrated learning task. See id. at 191-92.

25. For example, when the instructor gives students a list of statutes and cases for a closed memo, the research portion has been scaffolded and the analysis is narrowed to the universe of cases provided by the instructor. As the students become familiar with the law in that area, the instructor may add some cases, or add some facts for them to analyze, or may open up the research more broadly. In that way, the students are not overwhelmed by the breadth of the cases or the law as they make their initial attempts at analysis, but once they understand what has been provided, they are ready to delve deeper into the process of research or analysis. 
of scaffolding can disappear or even reverse if scaffolding continues. ${ }^{26}$ This disappearing competency is known as the expertise-reversal effect. As domain-specific schema increase, primary guidance, essential at an earlier stage of learning, may actually increase extraneous load as the experienced student can be distracted by being asked to reconsider previously-mastered information. ${ }^{27}$ Thus, as learning progresses, instructors must identify and employ the types of support most appropriate for each stage of the process.

\section{B. Students Learn Deeply What They Discover for Themselves}

One way to help students develop schema in legal analysis and writing is to base learning on their own reactions to reading legal documents, reactions which spring from knowledge they already have. The re-creation of user's experience to allow students to discover what is effective, and what is not, in written legal analysis is a modest example of the problem-based learning branch of discovery learning. Problem-based learning confronts students with open-ended real world problems to solve and requires students to "take the lead in defining the problem precisely, figuring out what they know and what they need to determine, and how to proceed to determine it." 28

Discovery learning theory proposes that students learn more deeply when they themselves have discovered concepts and skills than when the concepts and skills are the subjects of lecture or reading. As various educational settings have implemented and refined discovery learning, its usefulness for the teaching of concepts and skills, rather than facts, has been conspicuous.

Jerome Bruner first articulated discovery learning theory in an essay first published in 1962. The essay, "The Act of Discovery," is included in On Knowing: Essays for the Left Hand ${ }^{29}$ Bruner began from the tenet that rote learning among high

26. Slava Kalyuga, Schema Acquisition and Sources of Cognitive Load, in CoGNITIve LOAD THEORY, supra note 8 , at $48,51,58$.

27. Id at $57-58$

28. Michael Prince \& Richard Felder, The Many Faces of Inductive Teaching and Learning, 36 J. OF C. SCI. TEACHING 14, 15 (2007).

29. See Jerome S. Bruner, The Act of Discovery, in ON KNOWING: EsSAYS FOR THE LEFT HAND 81-96 (1962). 
achieving students often does not promote deep understanding of processes:

We know from studies of children who tend to be early overachievers in school that they are likely to be seekers after the 'right way to do it' and that their capacity for transforming learning into viable thought structures tends to be lower than that of children achieving at levels predicted by intelligence tests. . . [T]hey develop rote abilities and depend on being able to 'give back' what is expected rather than to make it into something that relates to the rest of their cognitive life. ${ }^{30}$

Bruner chose the term "discovery" because he hypothesized that the process of discovery promoted deeper learning: "to the degree that one is able to approach learning as a task of discovering something rather than 'learning about' it, to that degree there will be a tendency for the [student] to work with the autonomy of self-reward or, more properly, be rewarded by discovery itself." 31

Bruner theorized that only the exercise of problem-solving and the "effort of discovery" allow the student to "generalize what one has learned into a style of problem solving or inquiry that serves for any kind of task encountered. . . ."32 He advocated problem-solving exercises as a way of encouraging students to organize material "in terms of a person's own interests and cognitive structures" on the theory that material so organized

has the best chance of being accessible in memory. It is more likely to be placed along routes that are connected to one's own ways of intellectual travel. Thus, the very attitudes and activities that characterize figuring out or discovering things for oneself also seem to have the effect of conserving memory. ${ }^{33}$

In short, high-achieving students will more likely internalize or remember concepts and knowledge discovered on their own. ${ }^{34}$

\footnotetext{
30. Id. at 88 .

31. Id.

32. Id. at 94

33. Id. at 96 .

34. Bruner did not explicitly qualify every word he wrote about discovery learning by reference to a population of over-achieving students. In the chapter of On Knowing devoted to discovery learning, he identifies high-achieving students as most likely to bring all of
} 
Early efforts at implementing discovery in classroom settings, where the transmissionist models of lecture or lecture and drill had dominated, led to mixed and even poor results. ${ }^{35}$ Professor Carol Wiesner, commenting on the results of early research into the effectiveness of discovery methods of teaching as compared to the didactic methods they replaced, noted that didactic methods were demonstrably superior in preparing students for immediate retention tests. ${ }^{36}$ According to Joyce Castronova, a proponent of discovery learning in primary education, the available research comparing discovery methods and traditional methods suggests that discovery techniques are most effective in teaching skills and major concepts, where discovery promotes a "deep understanding." ${ }^{7}$ She acknowledges that "fact-based information" may be best taught and learned through traditional, transmissionist methods. ${ }^{38}$

Discovery learning may incorporate scaffolding to reduce cognitive load by identifying particular questions or aspects of a problem for students' close attention. Scaffolding in that form is sometimes referred to as an advance organizer and narrows the inquiry so that cognitive load limitations do not obstruct the discoveries the professor intends. ${ }^{39}$

their focus to bear on the immediate task and least likely to transform that learning into thought structures of longer-lasting utility. We assume that the majority of law students would qualify as over-achievers, at least when they arrive at law school.

35. See Carol Wiesner, A Comparison of the Effectiveness of Discovery Versus Didactic Methods and Teacher-Guided Versus Independent Procedures in Principle Learning, $65 \mathrm{~J}$. EDUC. Res. 217 (1971).

36. Id. at 217 .

37. Joyce Castronova, Discovery Learning for the 21st Century: What Is It and How Does It Compare to Traditional Learning in Effectiveness in the 21st Century?, http:/www.myenglishpages.com/files/1282044031.pdf (last visited June 15, 2015).

38. See id. Cf. Wiesner, supra note 35, at 219 ("It is surprising . . that the didactic method failed to show any advantage on the retention test in light of the fact that the discovery method did show some of its usual advantage on the delayed transfer test.").

39. The precise definition of the term "advance organizer" has been the subject of some debate. See David P. Ausubel, In Defense of Advance Organizers: A Reply to the Critics, 48 REV. OF EDUC. RES. 251-57 (1978). "The term advance organizer refers to information that is presented to the learner prior to instruction and that relates the new material of instruction to the learner's general background." John C. Peterson et al., The Effect of Organizers and Knowledge of Behavioral Objectives on Learning a Mathematical Concept, 4 J. Res. MATHEMATiCs EdUC. 76, 76 (1973). For purposes of this Article, the definition provided by Peterson et al. suffices to identify the instructions and questions provided to students before they undertake the exercises as advance organizers. 


\section{Advance Organizers Provide Scaffolding That Leads Novice Writers to Effective Schema}

As we have noted, an advance organizer is a form of preexercise scaffolding that narrows the students' focus. Scaffolding in that form prevents the cognitive load generated by a broad or free-ranging inquiry from impeding the discoveries the professor intends. The success of any discovery teaching method largely depends upon the instructor's ability to eliminate, to the greatest degree possible, extrinsic cognitive load.

In the exercises using samples described below, discovery learning promotes a deeper understanding of processes of legal analysis and legal writing. In each exercise, scaffolding is essential to achieving that objective. These discovery learning exercises do not replace other vehicles, including straight lecture and lecture and practice, for transmitting the same principles. The exercises are the starting points, however, for discussing some basic elements of analytical and writing doctrine that have been the central subject matter in the first-year legal writing and analysis course for the past two decades. ${ }^{40}$

The goal of learning is to move information from working memory into long-term memory by constructing schema. That goal frees working memory and reduces cognitive load. Information stored in long-term memory as schema generates negligible cognitive load, as it is always available.

One teaching challenge in the first-year legal writing and analysis class results from the fact that schema link new information to already-existing knowledge, and our first-year legal writing and analysis students often do not have appropriate pre-existing knowledge to which they can link the new information. Instead, these novices may link to schema from

40. Discovery learning is not new in the law school setting. A form of discovery learning, known as "case-based" learning, has been a principal teaching method in law schools for the past 120 years. In case-based learning, students study actual or hypothetical cases presenting scenarios they may encounter in professional practice to promote reasoning ability, the ability to "make objective judgments," and "the ability to identify relevant issues and recognize multiple perspectives," among other objectives. Prince \& Felder, supra note 28, at 16-17. Case-based learning is difficult to apply in teaching most other disciplines because instructors must create and analyze the cases themselves before employing them in the classroom. In law teaching, however, the availability of cases reduces the instructor's investment. Assuredly, other discovery teaching techniques have been used in the law school setting. 
other domains that do not appropriately inform the current task, resulting in misunderstood and misapplied learning. ${ }^{41}$

Advance organizers can prevent this potential miscategorization of learning. Advance organizers provide organizational structures that contain "concepts that are introduced in advance of the material to be learned and written at a higher level of abstractness, generality, and inclusiveness." 42 Each exercise described in this paper uses an advance organizer to help students focus on what is intrinsic to their learning at the moment, to develop a general domain framework, and to reduce the chances that the students will attach the new information to irrelevant structures from their own backgrounds. In the exercises described in part III instructions and questions focus the students on the kinds of information that they will be learning, but at a very abstract level. The exercise described in Part IV uses an already familiar rubric to organize the new information students are steadily acquiring about legal analysis and writing processes.

\section{LEGAL WRITING STUDENTS LEARN WHAT THEY DISCOVER ABOUT PROCESS: THE SAMPLE EXERCISES}

For many years, Monte has administered a judicial externship while also teaching the first year legal writing and analysis course. Monte's work directing the judicial externship program has permitted him to observe how upper-level students gain critical insights into analysis and writing processes by becoming users $^{43}$ of written legal analysis. The externship experience is a process of discovery for many of the upper-level students, a

41. Kalyuga, supra note 26 , at 51 .

42. Livingston Alexander et al., Facilitation of Learning and Retention of Oral Instruction Using Advance and Post Organizers, 71 J. EDUC. PsYCHOL. 701, 701 (1979); see also Susan A. Ambrose et al., How Learning Works: 7 ReSEArch-Based Principles for SMART TEACHING 53 (2010). For an extended description of advance organizers, see M. H. Sam Jacobson, Learning Styles and Lawyering: Using Learning Theory to Organize Thinking and Writing, 2 J. ALWD 27, 49-71 (2004).

43. "User" describes the role the students occupy in the externship program and the role students play in the exercises described. "Consumer" and "reader" are alternatives. None of the three is perfect in every instance. We have chosen to be consistent, rather than perfect, to reduce the extrinsic cognitive load imposed by the necessity of sorting out the subtle differences among the three terms. A "user" in this context is anyone who reads with a purpose beyond pure pleasure or entertainment. 
process that includes discovery of some basic doctrine relating to analysis and writing processes that Monte, as a teacher of firstyear legal analysis and writing, had been attempting to teach at that earlier developmental stage. In frustration, he recognized that the first-year legal writing and analysis course had been less than completely successful at teaching foundational doctrine of legal analysis and writing because the students lacked the user's experience of written legal analysis. Exercises using samples have helped to recreate the user experience for first-year students.

A. The Role of Models in Teaching Legal Analysis and

Writing and the Impediments to Duplicating the

Externship Discovery Experience for First-Year Students

The era when legal analysis and writing were taught using models of documents that students imitated has long since passed. The profession rejected this strictly "formalist" approach to teaching writing processes as inadequate preparation for independent legal writing and analysis. ${ }^{4}$ The shift away from models in legal writing instruction accompanied a shift to teaching students to write from the social perspective. ${ }^{45}$ The social perspective integrates into writing processes an understanding of the purposes for which a particular document is written, the identities of its audiences, and the needs of those audiences. ${ }^{46}$ Part of the New Rhetoric evaluates students' work, in part, by how well it fulfills the audiences' needs. ${ }^{47}$ The difficulty for the first-year law student in this paradigm for learning analysis and writing processes is that she does not know the audience for her first legal writing projects, and she has no basis for comprehending the audience's needs. She has no predicate for evaluating whether her work meets those needs until she has an empathy with the user. ${ }^{48}$

44. See J. Christopher Rideout \& Jill J. Ramsfield, Legal Writing: A Revised View, 69 WASH. L. REV. 35, 49-51 (1994) (describing the formalist approach to legal writing instruction); see also Terrill Pollman, Building a Tower of Babel or Building a Discipline? Talking About Legal Writing, 85 MARQ. L. REV. 896 (2002).

45. See Bari R. Burke, Legal Writing (Groups) at the University of Montana: Professional Voice Lessons in a Communal Context, 52 MONT. L. REV. 373, 400-02 (1991).

46. See Teresa Godwin Phelps, The New Legal Rhetoric, 40 Sw. L.J. 1089, 1094 (1986).

47. See Burke, supra note 45 , at 400

48. See Rideout \& Ramsfield, supra note 44, at 58. 
The upper-level students gain that empathy from their externship experiences. They occupy the position of the user and share the user's needs, frustrations, reasons for using written legal analysis, and goals. After the externship, as upper-level students tell it, they empathize with the user and keep the user's needs and goals in mind in their own written legal analysis.

So, while one of our most important goals as legal writing and analysis professors is to encourage our first-year students to take the needs of the users of their writing into consideration, we are stymied. The conundrum is that very few of our first-year students have ever used legal writing. When the upper-level externs go off to work on opinions in judges' chambers, they use attorneys' written product and, almost always for the first time, have a first-hand experience of what users need.

This conundrum found the germ of a solution in a new approach to samples. ${ }^{49}$ Since rejecting the strict formalist approach, legal writing and analysis professors have sometimes resisted models for a variety of reasons. We do not want to encourage reliance on models because we recognize that copying does not promote understanding; ${ }^{50}$ we fear that mechanical or unguided use of models will cause our students to become mechanical, unthinking writers. Those are legitimate reasons to avoid models or forms as primary teaching tools, but they are not reasons to reject samples for purposes other than to model or to promote copying.

Popular legal writing and analysis textbooks, recognizing that new law students lack real-world user experience, address the needs of some users of written legal analysis by describing those readers. Linda Edwards calls these users "law-trained readers." 51 She attributes certain characteristics to those users and generally describes the manner in which they engage with

49. At this point, we must credit an important source for our ideas in this Article. At the 2010 Legal Writing Institute (LWI) biennial conference, we attended Terrill Pollman's presentation entitled. "A Conversation About What Cognitive Scientists and Composition Theorists Know That We Don't About Using Examples to Improve Learning." In the course of that 45-minute session. Monte found the beginnings of a solution to his frustration. Professor Pollman is not responsible for our ideas, to the extent that they are misguided. She did plant the seed, however, for the use of flawed (or, shall we call them "realistic") samples to simulate the user or consumer experience for first-year legal writing students. Her work has culminated in the recent article, The Sincerest Form of Flattery: Examples and Model-Based Learning in the Classroom, supra note 16.

50. See Burke, supra note 45 , at $385-88$.

51. Linda H. Edwards, Legal Writing: Process, Analysis, and Organization 14954 (5th ed. 2010). 
written legal analysis.52 She suggests methods for anticipating their needs and guarding against their skepticism. ${ }^{53}$ The careful student will attempt to take that advice into account but not with the same confidence that is achieved when the behavior is a result of belief. Belief comes from personal experience of what one has discovered to be true. ${ }^{54}$

An answer to the unavailability of an actual user experience for first-year law students may be the approximation of that experience through problems presented in the classroom. Discovery learning theory provides the underpinnings for problem-based exercises to spark "the moment of insight when the learner grasps the organizing principle so that he sees the relationships among the facts before him, he understands the cause of the phenomenon, and he relates what he sees to his prior knowledge."55 So, exercises that allow first-year law students to share the experience of the user may let those students experience the same discoveries about legal writing and analysis that the judicial externs routinely have. Carefully designed discovery experiences may permit an even more complete understanding of the legal writing doctrine we want out students to learn.

52. See id. at $149-51$

53. See id. at $152-53$.

54. One very common shared insight about judges, in particular, is that "less is more" in persuasive analysis. This advice is based on the very real preference by most judges for concise analysis. See Kristen Konrad Robbins-Tiscione, The Inside Scoop: What Federal Judges Really Think About the Way Lawyers Write, 8 LEGAL WRITING 257, 278-81 (2002) (summarizing open-ended survey responses in which judges asserted that conciseness would increase the persuasiveness of advocates' writing). For the first-year law student, who has no experience as a judge or law clerk, however, that advice is meaningless and potentially detrimental. When judges say that less is more, they really mean that they appreciate clean and straightforward analysis based upon the best available authority and leading to a conclusion unassailable in light of that authority. They loathe diversions into ultimately extraneous subjects and unnecessary detail about earlier cases. Until a student has experience as a user of legal analysis, she cannot grasp the convincing quality of a concise analysis based upon directly applicable or readily analogous precedent, and she is likely to apply the less-is-more guideline in a fashion that results in incomplete analysis.

55. Julia M. Boleratz, Learning By Discovery: An Experimental Study to Measure Its Effectiveness for Teaching Value Concepts, 36 J. EXPERIMENTAL EDUC. 13, 13 (1967). 


\section{B. Discovery by Law Students Outside the Legal \\ Writing and Analysis Classroom and a Solution for First-Year Students Using Samples}

As part of the judicial externship program that Monte has administered for many years, students maintain journals in which they write weekly about their externship experiences. At the end of the semester, each extern writes a paper reflecting on the experience. In the program Monte administers, students are not given topics for these journal entries and papers, and they are free to write about anything related, even remotely, to the externship.

Given those broad parameters, they consistently choose, at rates of $65 \%$ to $75 \%$ of each semester's group, to write about how the externship experience has enlightened them, in one or more of three ways, with respect to legal writing and written advocacy. One group writes about basic failures in memoranda submitted to the courts. Those failures include non-existent or careless organization, the omission of a request for specific relief, and sloppy analysis. Another group focuses on failures in editing for conciseness or failures to apply persuasive technique. This group writes about groaning in dismay at the unnecessary length of some submissions, at the failure of the attorney to focus on a particular or effective legal argument rather than applying a scattershot approach, and at attorneys who appeal to emotion or personal values at the expense of persuasive and effective legal analysis. Students in the third group write about how their experiences with good and bad analysis and writing by other attorneys have illuminated strengths and weaknesses in their own work.

The externs are second- and third-year students, all of whom have completed at least the first-year legal writing and analysis courses before undertaking an externship. Monte found himself thinking over and over that the way he was teaching first-year students was like teaching the rules of basketball to a group of children and then telling them to play without ever seeing a basketball game, even the playground version. Then, when their game has ended, we send them to a game, and they come back saying, "Now, I get it."

The experience of the judicial externs usually cannot be provided to first-year students, but it can be approximated in a manner that provides first-year legal writing and analysis 
students the same opportunities to view legal writing and analysis from the perspectives of the user. Two exercises using samples allow students to interact with written legal analysis from the perspective of the user while they are not, themselves, engaged in analysis or writing.

The first exercise involves two predictive memoranda analyzing the same set of legal issues. ${ }^{56}$ Both memoranda are flawed in ways that differ from one another, but they realistic samples of attorney work. Students confront the memoranda at the very beginning of the semester, before students have read the portions of their textbooks that would acquaint them with the analytical and writing doctrine that guides legal writers in preparing such documents.

The students assume the role of a partner in a firm approached by a friend regarding a possible case of sex discrimination against her former employer. The students evaluate two purported memoranda from associates. They look for effective writing about the facts and the law, while at the same time noting what is missing or unclear in each document. Additionally, the students use the two memoranda to identify two or three basic principles about effective legal writing, expressed in their own words without consulting their legal writing textbook.

In class, students first share their answers to the questions. The professor guides the discussion by asking the students to elaborate upon the most salient insights. The students' insights are written on the blackboard or as digital comments on the projected memoranda. The students generally discover the major flaws in the memoranda. They also note effective aspects.

The students then share the principles for effective legal writing that they have gleaned. After some in-class discussion refines and clarifies the principles, mostly by consensus of the students but with some guidance by the professor, the professor summarizes the principles. They often include some variation of these insights:

1. The question presented should be specific about the facts necessary to resolve the issue.

56. Two is not a magical number in the design of this exercise. Three or more short memoranda would expose students to a richer set of flaws and strengths but would also increase the cognitive load. 
2. The facts should focus on the controversy that the question presents.

3. Early in the memo the writer should give an accurate idea about where it is going.

4. The discussion of the law should be specific about the parts of the law that will resolve the dispute.

5. When authority cases are discussed, the writer should be clear about the law and not just relay the facts and the outcome, requiring the reader to figure out what rule the court was applying.

6. The writer should clearly identify the specific rule that will answer the question presented.

7. The conclusion should clearly follow from the discussion of the facts and the law.

Later in the semester, as the textbook and classroom lecture and discussion introduce elements of legal writing and analysis doctrine, the professor refers back to the principles in the summary, replacing the phraseology with the standard vocabulary associated with each element.

The second exercise involves two client letters addressing the same legal issues. The letters address a client who is not an attorney but an educated, professional person. As with the memoranda, the letters are realistically flawed examples of attorney work. Students confront the letters before they have read the portions of their textbooks that would acquaint them with the doctrine that guides legal writers in preparing communications to clients.

When students share their principles for effective client letters in class, they have once again identified valid and important principles of effective written communication.

C. The Efficacy of the Exercises in Practice and Some Support from Learning Theory

In practice, two benefits derive from the exercises using samples. First, in classes that have used the sample exercises, they have reduced two common undesirable phenomena. The first is resistance to anything that sounds like a formula. In our experience, novice legal writers often express reluctance to embrace rules or formulae in any creative endeavor, and some 
express variations of a belief that something as intellectual as legal analysis should not be reduced to formulae. The development of principles by the students themselves before beginning any assignment appears to have largely eliminated that resistance. In class, the students' principles are connected to the doctrine included in their reading and in-class lectures and discussion. The students already know and believe the principles, having discovered them, and appear to be less likely to reject or question them. The students who have encountered the samples before beginning to practice their own legal writing and analysis tend not to view the principles as formulae at all but as guidance for the effective written presentation of legal analysis. For example, the order of the rule and application (the " $\mathrm{R}$ " and " $\mathrm{A}$ " of IRAC or CREAC) is viewed not as a formula but as a recognition of the user's need to know what the rule is before considering analysis or argument about how the rule applies to a particular set of facts. It is no longer a formula but a belief based upon the personal experience of the user.

The second perceived benefit is that the students have incorporated, in their first drafts of each assignment, the internal organizational principles they have "discovered" in the exercises to a greater extent than students often did in classes that did not use the sample exercises. This effect has been consistent through four academic years.

The apparent results of the sample exercises may support a hypothesis that first-year legal writing and analysis students understand more deeply the principles they have discovered on their own than those they learn through less student-centered teaching methods. This hypothesis finds support in discovery and problem-based learning theory.

We did not design the sample exercises as discovery learning experiments or with an eye to reducing cognitive load. Their design is, nevertheless, consistent with the structure of successful exercises grounded in the problem-based learning branch of discovery learning. Additionally, the exercises provide experience with a complex task, understanding a legal analysis, and the scaffolding needed at the beginning of the semester. In both exercises, the instructions and questions given to the students before they interact with the documents put the students in a particular frame of mind and narrow their inquiry. Accordingly, the exercises were guided discovery experiences. 
The written instructions provided to the students serve as scaffolding in three significant ways. First, they prescribe point of view. Students interact with the samples from the point-ofview of (a) a senior attorney who does not know the legal subject matter and requires assistance in advising a client or (b) a sophisticated, non-lawyer client. The instructions narrow the possible points of view the students might have chosen and, therefore, eliminates extrinsic cognitive load related to that choice. The point-of-view instruction generates some cognitive load of its own, requiring the students to observe from the perspective of someone other than themselves. That other person is substantially like the students, however, in the sense that the senior lawyer, the sophisticated but untrained client, and the students are intelligent but uninitiated readers as to the subject matter of the memoranda. The students can generate a mindset of naiveté about the specific area of law because it approximates their own mental state.

The instructions and guidance serve as advance organizers. In addition to prescribing a point-of-view from which to view the documents, the instructions guide what the students should be looking for in the documents. By eliminating the students' need to make decisions about their own documents, cognitive load is reduced in at least the following ways:

1. The students are not required to determine a role for themselves;

2. The students are not required to identify the appropriate vocabulary for their insights and principles (the instructions advise them to use their own words);

3. The students are not required to opine upon which sample was better;

4. The students are instructed to assume that they are not experts in the pertinent area of law, in the memorandum exercise, and that they have only a layperson's understanding of the law, in the client letter exercise;

5. The students are not required to connect their insights to principles;

6. The students are not required to identify the standard nomenclature for any of their discoveries; 
7. The students are not required to fit their insights into any pre-learned category or formula and, therefore, are not required to remember a formula; and

8. The students are not required to plan and perform their work to achieve a grade or to succeed in any performance assessment.

The instructions and questions allow the students to interact with the samples from a familiar point of view: intelligent ignorance. They can bring to bear exactly the knowledge they already possess about what is comprehensible, what is clear, what is helpful, and what is convincing. In that sense, the students are in a position, as a result of the instructions and questions provided by the professor, to "relate[ ] the unfamiliar new material to be learned to some general background the students [were] assumed to have." ${ }^{57}$ Accordingly, the instructions and questions perform the essential function of an advance organizer. ${ }^{58}$

To the extent that the instructions and questions constitute advance organizers, the success of the exercises as discovery learning is conditioned upon the appropriateness of the design of the instructions and questions. Effective advance organizers are "appropriately relevant and inclusive introductory materials . . . introduced in advance of learning . . . and presented at a higher level of abstraction, generality, and inclusiveness . . .."59 The test of the appropriateness of the advance organizer is its ability "to provide ideational scaffolding for the stable incorporation and retention of the more detailed and differentiated material that follows . . ..."60

Exercises using samples in the first-year legal writing and analysis course bring the students' focus to legal writing doctrine by requiring them to judge the effectiveness of the work of legal

57. Thomas A. Romberg \& James W. Wilson, The Effect of an Advance Organizer, Cognitive Set, and Post Organizer on the Learning and Retention of Written Materials, $4 \mathrm{~J}$. Res. Mathematics EdUC. 68, 69 (1973).

58. See id. ("An advance organizer is designed to bring to the students' attention assumed previous knowledge that is related to the content to be learned"); see also Marilla D. Svinicki, A Theoretical Foundation for Discovery Learning, 275 ADVANCES PHYSIOLOGY EDUC. S4, S6 (1998) ("Discovery learning is more meaningful because it makes use of your own personal associations as a basis for understanding." (Emphasis in original)). Students are not learning in a vacuum but basing new knowledge on personal experience.

59. David P. Ausubel, Educational Psychology: A Cognitive View 148 (1968)

60. $I d$. 
writers other than themselves. The instructions and questions provided to students before they interact with the samples direct and narrow the students' focus to permit them to observe the relative effectiveness of the samples. In sharing their insights and the principles they have identified, the students demonstrate that they can identify the embedded flaws in the samples as well as strengths. In that sense, the instructions and questions succeed as advance organizers, whether or not they are perfectly designed.

The exercises serve as scaffolding in the discovery learning process in another, entirely separate fashion: they provided students a means of learning about analysis and writing processes apart from the production of a legal document. This separation of process and product was the goal in the design of the exercises.

The adoption of discovery teaching techniques imposes some burdens on the teacher: stresses on the syllabus and "intellectual demands on the teacher." 61 These demands include sufficient depth of subject matter knowledge properly to guide the experience and the ability to "perceive and understand" what the students are attempting to express about their own learning. ${ }^{62}$ Despite these burdens, both learning theory and the anecdotal evidence of experience suggest that these stresses are outweighed by the pedagogical benefits of the sample exercises or similar means that allow students to learn doctrine related to processes of legal analysis and writing free of the cognitive overload generated by teaching methods that combine product and process. If discovery and problem-based learning permit us to teach legal writing and analysis doctrine in an environment in which novice writers bring ample working memory to bear on the task, the tension between product and process is reduced. We can achieve one of our primary goals: bringing students to a deep understanding of processes that result in effective written legal analysis.

61. David Hammer, Discovery Learning and Discovery Teaching, 15 CoGnition \& INSTRUCTION 485, 517 (1997).

62. Id. at 518. "It is time-consuming to construct authentic open-ended problems whose solution requires the full range of skills specified in the instructor's learning objectives. ..." Prince \& Felder, supra note 28, at 16. 


\section{STUDENTS LEARN ABOUT WRITING PROCESSES BY CRITIQUING NOVICE LEGAL WRITING: THE RUBRIC EXERCISE}

Novice legal writers often do not have the information needed to assess what makes an example in the text strong nor to assess the ways in which their documents differ from the example. 63 However, as discussed above in the context of the sample exercises, students can describe when a document conveys desired information and when it does not. This insight was the catalyst to an exercise we now routinely use in first-year classes. In it, we show students a weak example and ask them to describe the strengths and how they would approach remedying the weaknesses. ${ }^{64}$

\section{A. Using a Rubric as an Advance Organizer to Scaffold}

In the exercise, first-year legal writing and analysis students are given a research memorandum drafted by a student with little legal writing experience. The students are tasked with providing feedback to the student and critiquing the memorandum. A rubric helps students identify and categorize the strengths and weaknesses of the memorandum. The professor has previously given the students the same rubric and has discussed it with them before they have written the first drafts of their own research memoranda. The professor has used the rubric to critique their first drafts, and the students have received their individual rubrics with their critiqued drafts. Thus, the students are familiar with that tool, have used it as a guide while writing their first drafts, and have received feedback on a copy of the rubric and on their documents themselves.

63. See Christine N. Coughlin et al., See One, Do One, Teach One: Dissecting the Use of Medical Education's Signature Pedagogy in the Law School Curriculum, 26 GA. ST. U. L. REV. 361, 380-81 (2010) ("Even when a professor provides more than one sample for students, inadequate comparative discussion of the strengths and weaknesses of each document leave the students confused to why some examples are better than others.").

64. See id. at 389 ("Providing a deficient sample, without disclosing its quality, before showing students a thorough, well-written sample can effectively allow students to simulate a reader's experience and understand why incomplete or sloppy analysis impedes a reader's understanding. Students are then more apt to understand why the better sample meets the reader's needs and communicates the analysis more clearly." (Footnote omitted)). 
In the exercise, the students assume the professor's role and use the rubric to guide their feedback. The rubric reminds them to include positive feedback, to find several areas where the writer could improve, and to prioritize for the writer where he or she should begin addressing the identified weaknesses. The class discusses the strengths and weaknesses of the memorandum, focusing first on successful aspects and the most helpful techniques used to convey the law and its application to the facts. In general, the students can identify what succeeds. ${ }^{65}$

During the class discussion, the professor refers students back to the rubric both to guide the students' thinking about how a writer should structure a memorandum and to reinforce the emerging vocabulary that the class will continue to use throughout the semester. For example, if students state that they do not understand a particular case, the professor asks questions about "rule explanation," reinforcing the terminology from the rubric and the text.

Once students have discussed the merits of the paper, the analysis turns to what made the paper difficult to follow or otherwise inadequate. Again, the rubric provides students with categories and language, and their own experiences of the weak aspects of the paper inform them. Most students indicate that the case-apply-case-apply analytical structure used by the memorandum's author leaves them uncertain of the legal rules. They add that they have found the discussion of a single authority case to be insufficient to thoroughly explain the law. Finally, they note that they have found mechanical errors distracting.

After the discussion, the students write anonymous "minute papers" responding to the prompt, "What did you find most valuable about this exercise? What did you learn from the exercise?" The minute papers serve two purposes: (1) to determine whether the exercise adds sufficient value to the course to continue using it in subsequent semesters; and (2) to reinforce for individual students what they have learned from the exercise. Some

65. Occasionally a student would find the case-apply-case-apply format "helpful." Asking other students whether they found it helpful usually resulted in the class agreeing that the format left them with questions about the law. A general statement about needing to write for an audience more like the rest of the class can assuage any uncomfortable feelings that the original student may have had about being in the minority, rather than being "wrong." 
of the students' responses from the minute papers are discussed below.

The most telling aspect of the minute papers is that none of the students write that the most valuable element was learning about the substantive law. Instead, they focus almost entirely on process. This outcome is consistent with cognitive load theory, which in turn explains why this exercise may help students more deeply understand writing processes.

B. The Efficacy of the Exercise for Bringing Students'

Focus to Writing Processes and Support from Learning Theory

Several characteristics intrinsic to the memorandum are vital to the exercise's success. First, the sample memorandum analyzes a topic completely new to the students with the goal that they assess the memorandum's success or failure at educating them on the point of law. Rather than reading another take on their own memorandum topic, the exercise forces students to use the sample memorandum as their only source for understanding a new area of law.

The second critical characteristic is that the memorandum contains many weaknesses common to novice legal writers, as well as some that students generally avoid. The common weaknesses include: an insufficient roadmap paragraph; failure to fully analyze authority cases; failure to synthesize cases, resulting in a case-apply-case-apply structure; typographical errors; and a conclusion that fails to summarize adequately. The less common errors include a failure to use subheadings. ${ }^{66}$

As with the sample exercises described in part III of this Article, the use of valuable class time for an exercise that asks students to use a rubric to evaluate a weak paper on a legal topic

66. The weak memorandum was Terri's first legal writing paper, a fact not germane to the success of the exercise as it relates to cognitive load. However, some additional benefits derive from the use of the professor's own early work. See Terri L. Enns, Students Critiquing Novice Writing: Building Hope by Building Bridges, 48 DUQ. L. REV. 403, 42122 (2010) (arguing that critique of the legal writing faculty's novice writing builds a relationship of trust). Of course, one reason to include mistakes that the students would not make is to let them feel good about their own papers, as they have, at least, avoided the obvious mistakes made by the writer, even if their own papers include all of the more common errors. 
on which the students will not be writing raises a variety of concerns. What follows responds to some of those concerns and includes support from students' minute papers.

\section{The Benefits of the Exercise}

Some professors may object to providing the grading rubric to students, fearing that the rubric discloses too much information to the students and will result in overly-similar papers, making distinguishing between papers for grading purposes difficult. In practice, however, the students' exposure to the rubric has not had that effect. The rubric serves as an advance organizer, providing the structure and language that will be used throughout the semester and fostering the formation of schema that can lead the students toward deeper understanding of writing and analysis doctrine. Cognitive learning theory advises that firstyear legal writing and analysis students are cognitively overloaded and that requiring students to memorize and conquer, all at once, all the attributes of a strong legal analysis and organization increases the extrinsic load rather than advancing learning. As the semester progresses, the rubric can become more detailed and the grading system can reflect the increased complexity. As students develop schema for the elements of effective legal writing and analysis, they will reduce their reliance on tools like rubrics, but that level of expertise is not the starting point for most first-year students.

Another conceivable concern is that the discussion of the novice writer's memorandum is insufficiently sophisticated to be worthy of an entire fifty-minute class session. The benefits of the exercise go beyond the discussion of the relative merits of the memorandum, however. The rubric reminds students of the vocabulary used in the textbook and in in-class lecture and discussion, as well as the legal writing doctrine that is the focus of the course, and in-class discussions have proven more fruitful than frustrating. Two factors of the exercise make that benefit possible: the memorandum is someone else's work, and the students' own egos are not at risk. These factors scaffold the learning process by reducing the load required to identify weaknesses in one's own writing and to preserve one's own psyche. In practice, students do not fear that pointing out a weakness reveals the same weakness in their own writing. The following 
quotes provide a sampling of the kinds of insights the students' experience:

- "The exercise was valuable because it helped me see what/who the 'skeptical' reader is and how to write for them. Also showed how important using the CREAC structure is."

- "Helpful to see why/where citations are needed. Good to see why extensive support for rule explanation is key. I didn't realize it before, but organization is very important." 67

- "This exercise was great for dissecting all the sections. It was better for me than analyzing my own work."

- "It was helpful to read about an issue that I was unfamiliar with because it really demonstrated how clear I should be about the rules. Need umbrella section. Follow CREAC. Be sure to back up rules with cases . . more than one." 68

A consistent theme in these comments and those of other students was the benefits to be derived from experiencingdiscovering - the impact of an unsuitably organized document. Even at an early stage in their legal training, the first-year students could see that the particular structures that legal writing doctrine requires are valuable for understanding and communicating a legal problem and its analysis. The students used the vocabulary of the domain-"rule explanation," "CREAC," "umbrella section" - to express those structures and the ways that those structures affected students' understanding of the legal analysis.

A third possible concern about this exercise in the first-year legal writing and analysis course is that first-year law students cannot internalize and then transfer the insights from reading and discussing the weak memorandum to their own papers. However, excerpts from the minute papers, reflected in the following comments, suggest otherwise:

\footnotetext{
67. Experiencing the lack of clear organization helped this student to recognize its value.

68. Note that the student immediately applied learning to the student's own work: "I should be...."
} 
- "I learned that it would/will be beneficial to critique my paper in this way (more formally) to find my own weaknesses. I will use the grading sheet and self-grading materials to improve my memo."69

- "The exercise stressed the importance of reading one's own work with a skeptical eye as it is much easier to critique when you are removed from the work. Also, shines light on the usefulness of CREAC or a similar structure as I think it follows from what comes naturally logical and understandable."

- "This exercise was valuable because it gave me a chance to step back from my role as writer and into the role of the grader. Helped me pick out obvious mistakes and what was annoying to see. It was painfully obvious how much explanation was lacking and how it didn't seem reliable. I liked the exercise."

- "I learned the perils of assuming knowledge of background info."

- "The importance of objectively re-evaluating the memo as a whole and then the individual problems. Also, at this stage, the value of prioritizing changes to make."

- "It was fun to step inside the shoes of the professor/grader to see what things they look for when grading, to realize where improvements can be made in our own papers. It will be a useful exercise to try on our own papers."

This last quote provides valuable insight into student thinking, as it indicates that when the student was writing his or her own paper, the student did not think to use the rubric as a guide, even though it had been provided and discussed in class prior to the submission of the first draft of the memorandum. This failure on the part of the student to take advantage of a tool that was readily available echoes the observations in the introductory section of this Article: students become consumed with producing a

69. See Mary Beth Beazley, The Self-Graded Draft: Teaching Students to Revise Using Guided Self-Critique, 3 LEGAL WRITING 175, 194-200 (1997) (providing as appendices "Macro Draft Self-Grading Guidelines Office Memo" and "Micro Draft Self-Grading Guidelines Office Memo"). 
product to the detriment of learning the processes of writing and analysis.

A final concern about this critiquing exercise in the first-year legal writing and analysis course may come from fears about exposing novice legal writers to weak writing. The following comment from a student's minute paper clearly articulates the value of the exercise:

- "Seeing a paper that needed improvement was much more helpful than seeing a paper that did everything right. It helps to see why the issues are such a problem."

One remaining issue arises from placing the students in the "professor" role rather than asking them to approach the memorandum as a more general legally-trained reader. After initially considering assigning the students to the more common supervising attorney or partner role, Terri places the students in the role of professor for several reasons. Playing the role of the professor requires the students to critique the document for elements beyond whether the analysis effectively conveys the law to them as users of the memorandum. The added layer of critique relates to the professor's obligation to the legal writing student that differs from the obligation to the ultimate user of the memorandum.

In addition to determining whether the author of the memorandum correctly understood the legal analysis, the students as "professors" evaluate multiple elements of the document for their impact on the document's readability. The students articulate both strengths and weaknesses of the document. Rather than simply dismissing either parts or the whole as unintelligible, the students must look more deeply at the document to find which of the writer's choices succeed and which reduce clarity and reliability, applying their budding understanding of legal writing doctrine. Last, occupying the role of the professor, the students must articulate their critiques using domain vocabulary. They recognize that they cannot simply state that the writing is "unclear" and instead have to dig into their new knowledge base to find the language of their new discourse community. Ultimately, placing the students in the role of the professor reinforces a number of the class objectives, including understanding the need to accurately identify legal issues, the role of authorities, the need to synthesize cases, the role of organization for 
communicating legal analysis, and the impact of grammatical and citation errors.

\section{Support from Learning Theory for the Efficacy of the Exercise}

Two aspects of the exercise critical for reducing cognitive load are evaluating writing that is not the students' own and using a rubric. This exercise typically takes place in the middle of the semester, later in the learning process than the sample memorandum exercise described in part III of this Article. Accordingly, the students approach the sample document with different background information than they bring to those earlier exercises. Students have already written a draft, guided by a rubric. They are now ready to move toward a final draft and thus benefit from reducing extrinsic cognitive load that hinders them in their efforts to assess their own analyses and writing.

Evaluating someone else's writing reduces cognitive load in a number of ways. Writing is a highly personal exercise, and students can feel vulnerable when evaluating their own work. ${ }^{70}$ By allowing them to talk about weaknesses in someone else's writing, the exercise reduces that vulnerability, even when the students see that the errors resemble those that they were making in their own writing. Also, seeing that other writers make mistakes can reduce feelings of isolation or incompetence. By reducing defensiveness, the exercise can reveal students' own writing processes.

Finally, the exercise reduces cognitive load in ways similar to the exercises in Part III, including the following:

1. The students are not required to determine a role for themselves, as they are asked to place themselves in the role of the professor;

2 . The students are not required to identify the appropriate vocabulary for their insights and principles, as the rubric provides the vocabulary used by the course text and during class;

70. See, e.g., Daniel L. Barnett, Triage in the Trenches of the Legal Writing Course: The Theory and Methodology of Analytical Critique, 38 U. TOL. L. REV. 651, 672 (2007) ("Students often feel vulnerable and insecure when receiving criticism about their analysis." (Footnote omitted)). 
3. The students are not required to assign a grade to the memorandum as experts but instead assess strengths and weaknesses based on their own experiences as readers;

4. The students are instructed to assume that they were not experts in the area of law that was the subject of the memorandum;

5. The students are not required to remember the principles of a good memorandum, as the rubric provides that information; and

6. The students are not required to plan and perform their work to achieve a grade or to succeed in any performance assessment.

The rubric in the exercise reminds students of elements of strong legal writing and analysis. At the early stages of first-year writing courses, there is no reason to require students to remember all of these elements or to ask them to continually refer to the text to find those terms and concepts that the professor is trying to teach and, perhaps more importantly, on which the professor will evaluate students. Providing the rubric for students to use during this exercise, for students to use while writing, for the professor to use while grading, and for the two to use while in conference reduces extraneous load. As the students became more familiar and practiced in providing written analysis using the structures outlined in the rubric, the need for that scaffold declines because the students have constructed appropriate schema.

The minute paper responses, as well as the students' final drafts of their own memoranda, demonstrate that the reduction in cognitive load made possible by the exercise's design has moved the students toward one of the ultimate goals of the course: to learn processes of analysis and writing in addition to creating specific written products. The students learn foundational legal writing doctrine, including the importance of structure, the need for thorough and complete analysis, and the role of authority. They also learn more deeply about writing processes, including the need to view their own writing objectively and the value of applying a rubric. 


\section{CONCLUSION}

The first-year legal writing and analysis course schedule is packed with writing activities, but, in designing it that way, we may have overlooked the cognitive load impediments that guarantee that students will not learn much about analysis and writing processes simply by writing and receiving feedback. By clearing space for students to focus on processes of analysis and writing, we can come closer to ensuring that cognitive load does not interfere with students' acquisition of the foundational doctrine we want to impart. Greater understanding and adoption of that doctrine should improve the students' ability to transfer their new knowledge to new analysis and writing tasks. 